\title{
Tapeworm Induced Recurrent Pancreatitis: A Case Report and Review of Literature
}

\author{
Abdulmalik Altaf*, Rawaa Alnabulsi, Turky Alsubahi, Nisar Haider Zaidi \\ Department of Surgery, Faculty of Medicine, King Abdulaziz University, Jeddah, Saudi Arabia \\ Email: drnhzaidi@hotmail.com
}

Received 12 October 2013; revised 9 January 2014; accepted 8 February 2014

Copyright (C) 2014 by authors and Scientific Research Publishing Inc.

This work is licensed under the Creative Commons Attribution International License (CC BY).

http://creativecommons.org/licenses/by/4.0/

(c) (i) Open Access

\begin{abstract}
Recurrent idiopathic pancreatitis is an uncommon disease. We are presenting a case of Taenia saginata causing pancreatitis, which is rare in the literature. A 40 years old female was admitted to our hospital with complaints of epigastric pain for 6 months, radiating to the back, combined with nausea, vomiting and significant weight loss. On examination, she looked ill, vitally stable, afebrile, not jaundiced, and her abdomen was soft, lax with moderate epigastric tenderness, no distention and positive bowel sounds. Her workup showed serum amylase of $1367 \mathrm{U} / \mathrm{L}$, Liver function test, Calcium and Triglycerides were all within normal ranges. Abdominal Ultrasound showed homogeneous bulky pancreas with dilated pancreatic duct. CT abdomen confirmed the diagnosis of pancreatitis with no evidence of biliary stones. An upper gastrointestinal endoscope revealed diffuse gastritis with small haital hernia. She was treated conservatively as a case of idiopathic acute pancreatitis and later was discharged in good condition. One month later, she was admitted again with similar symptoms and attacks of diarrhea. Investigations showed amylase of $139 \mathrm{U} / \mathrm{L}$, abdominal Ultrasound was negative for biliary stones. CT showed a prominent pancreatic duct and thickened duodenum. Oesophagogastrodudenoscopy was repeated to evaluate the cause of the pain. This interestingly revealed a tapeworm (Taenia saginata) in the second part of the duodenum, adjacent to ampulla of Vater. The patient received Mebendazole $100 \mathrm{mg}$ PO BID for three days and later was discharged home. At 4 weeks follow up, she was asymptomatic and her stool analysis was negative.
\end{abstract}

\section{Keywords}

Recurrent; Idiopathic; Acute; Pancreatitis; Taenia saginata

\footnotetext{
*Corresponding author.
} 


\section{Introduction}

Recurrent idiopathic pancreatitis needs rigorous investigations in order to reach the cause. In $10 \%$ of cases of acute pancreatitis and 30\% of recurrent pancreatitis the aetiology is unknown. Marseille was the first to use the term Acute Recurrent Pancreatitis (ARP) [1]. It is described as the existence of no less than two documented incidents of pancreatitis in a patient without chronic pancreatitis (CP) at imaging. An in depth clinical history of recent infectious diseases, abdominal trauma or surgery, systemic diseases, alcohol, medicine intake, serum calcium, triglycerides levels, liver enzymes and autoantibodies (ANA, IgG4, rheumatic factor); and a minimum of one abdominal Ultrasound should be done in order to label them as idiopathic acute pancreatitis [2] [3]. Despite the long list of investigations, the etiology of pancreatitis in some cases will still be unexplainable.

Pancreatitis caused by helminths is rare and is usually diagnosed by coincidence. Helminths infestation is a leading health problem in underdeveloped countries. Common parasites, which can cause pancreatitis, are Ascaris lumbricoides, Clonorchis sinensis, Echinococcus granulosus, Toxoplasma, and Cryptosporidium.

A rare parasite that can cause pancreatitis is Taenia saginata, which is the most common pathogenic cestode in humans [4] [5]. Taenia is transmitted by consumption of raw beef meat, which contains larva [cysticerci], and patient passes proglottids in stool [6]. Reports on Taenia saginata causing pancreatitis are insufficient in the literature. In this report we present a case of recurrent pancreatitis induced by Taenia saginata.

\section{Case Report}

A 40-year-old Sudanese female, who is known to be diabetic (type 2), hypertensive and hypothyroid, was admitted to our institution with the complaint of vague epigastric pain for the past 6 months. The pain sensation radiated towards the back and it was associated with postprandial nausea and bilious vomiting, while having normal bowel habits. She had history of anorexia, considerable weight loss of about $14 \mathrm{~kg}$ and persistent fatigue. There was also a history of milder similar episodes in the past, without seeking medical advice. There was no history of abdominal trauma, alcohol use, recent travel, or family history of a similar condition. Furthermore, she was on insulin, amlodipine and thyroxin but wasn't taking any medication that is known to induce pancreatitis.

On examination, she looked ill, hemodynamically stable, afebrile and not jaundiced. Her abdomen examination indicated moderate epigastric tenderness, no distention and positive bowel sounds. Her investigations showed Amylase of $1367 \mathrm{U} / \mathrm{L}$ with normal biilirubin and liver enzymes. Calcium and triglycerides were within normal levels. Abdominal Ultrasound was done twice during admission, both of which were negative for biliary stones. It showed homogeneous bulky pancreas with a dilated pancreatic duct. CT abdomen and pelvis was confirmatory for the diagnosis of uncomplicated pancreatitis and negative for any radio-dense biliary stones. An upper gastrointestinal endoscope revealed a small haital hernia and diffuse gastritis positive for Helicobacter Pylori. The patient was resuscitated with IV fluids immediately, after that she was managed and treated conservatively as a case of idiopathic acute pancreatitis. Observation as an inpatient lasted for 5 days and later was discharged in good condition on oral Omeprazole and painkillers.

One month later, the patient was admitted again complaining of a similar clinical picture to her previous admission. She gave history of serious unintentional weight loss, a total of $25 \mathrm{~kg}$ over the past 5 months. She had history of intolerance to oral intake and attacks of diarrhea for which she had several ER visits. On investigation, amylase was of $139 \mathrm{U} / \mathrm{L}$. Abdominal Ultrasound was negative for biliary stones. CT showed a markedly enlarged pancreatic duct (Figure 1) and thickened duodenum with no other significant pancreatic changes compared to the previous study. Oesophagogastrodudenoscopy was repeated to evaluate the cause of the pain and to exclude other causes. Interestingly, a tapeworm (Taenia saginata) was clearly seen in the second part of the duodenum, adjacent to ampulla of Vater (Figure 2 and Figure 3). The patient was treated upon the Infectious Diseases consultation team request, with Mebendazole $100 \mathrm{mg}$ PO BID for 3 days and was discharged home once her pain and diarrhea subsided. The patient visited the ER again after three days for similar complaints, where she was treated with painkillers and IV fluids. Magnetic resonance cholangiopancreatography (MRCP) was done for further evaluation revealing beaded appearance of the pancreatic duct with maximum diameter measuring about $4 \mathrm{~mm}$ (Figure 4), Unremarkable gall bladder and common bile duct. At follow up, 4 weeks later she was asymptomatic and was tolerating her oral intake well. Stool analysis was negative. 


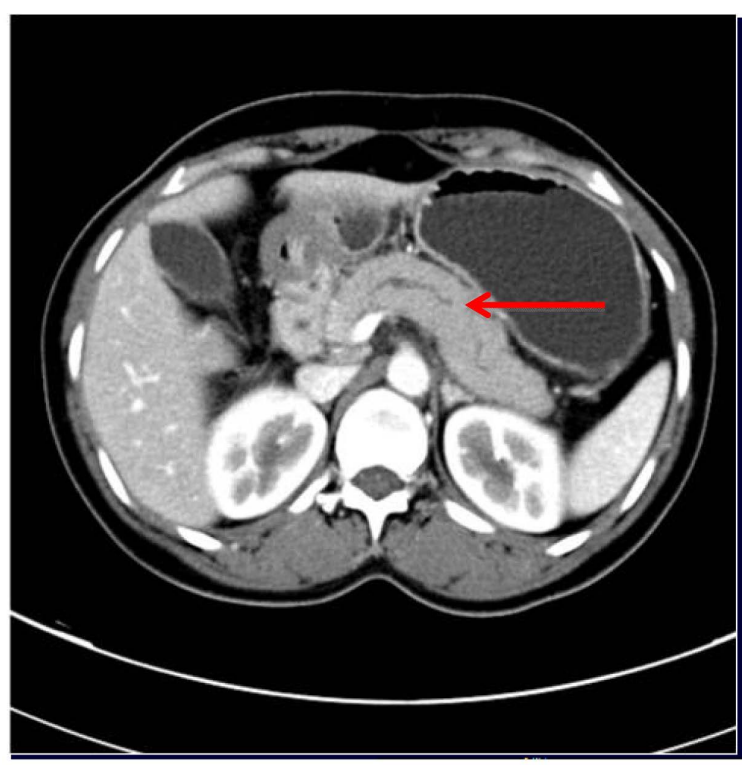

Figure 1. CT scan-pancreatic duct dilatation.

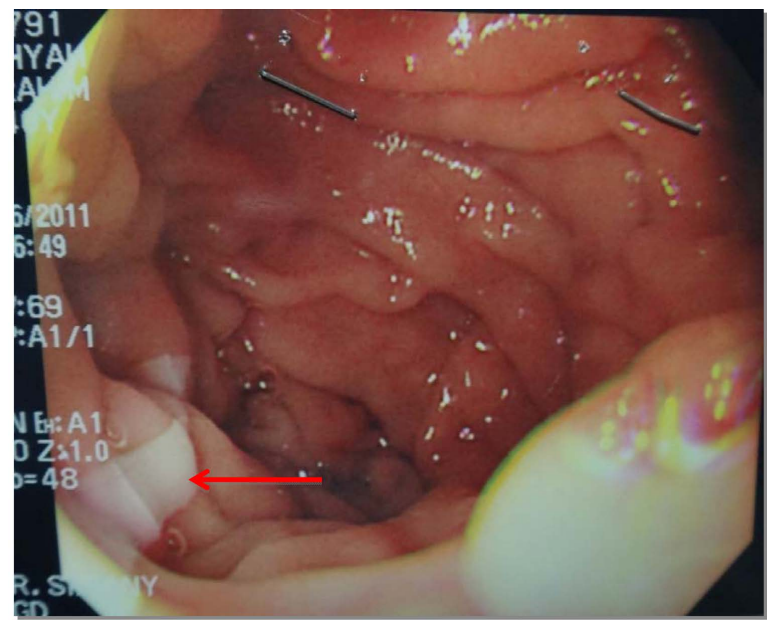

Figure 2. Taenia in duodenum.

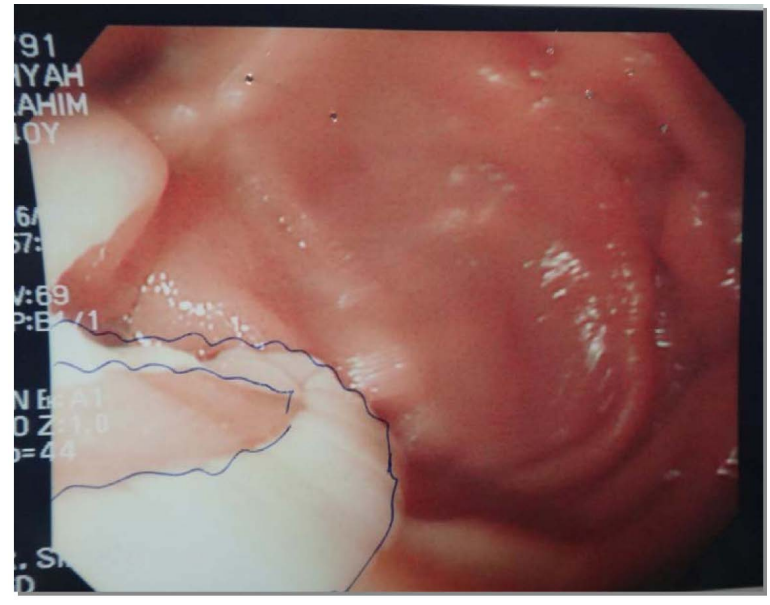

Figure 3. Taenia adjacent to ampulla of Vater. 


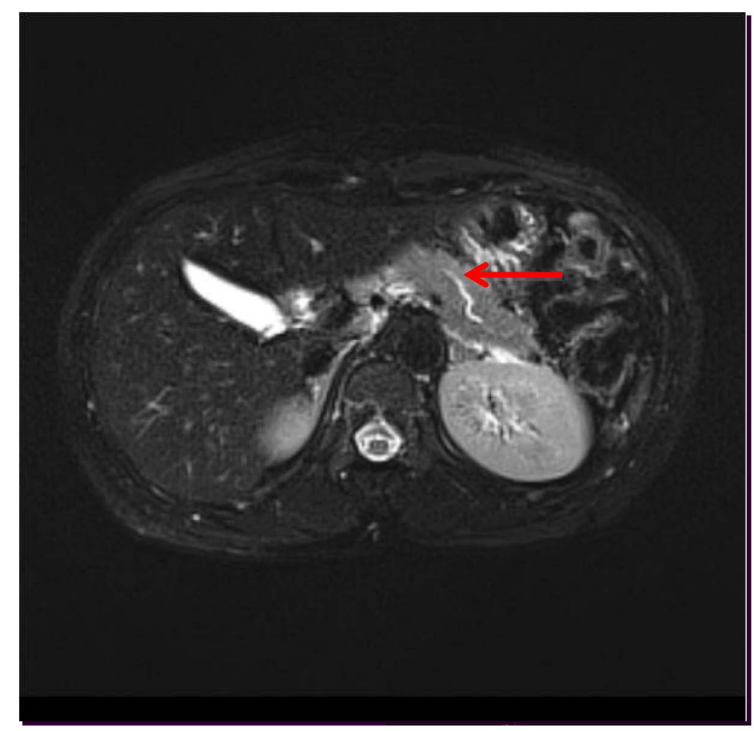

Figure 4. Pancreatic duct-beaded appearance.

\section{Discussion}

Helminths infestation is common worldwide and is also found in the Middle East part of the world. The mode of transmission is by eating raw beef, comprising the larval stage, which is known as cysticercus. Afterwards, it provokes the upper gastrointestinal tract; by the adherence of the cysticercus to the mucosa of the small intestine and hooks through scolices, which in turn gets transformed to a mature tapeworm. The indicated maturation process takes 10 - 12 weeks for Taenia saginata to fully mature. Taenia saginata causing cholecystitis is reported in the literature [7] [8] while choledocholithiasis is associated with ascaris [9]. The mechanism of ascaris causing pancreatitis is the migration of ascaris into the biliary tract through ampulla of Vater [10]. A similar mechanism can be explained for taenia causing pancreatitis as proglottids of taenia are mobile and can enter the ampulla of Vater. Taenia causes pancreatitis by occluding the pancreatic duct as well as by releasing secretions, which can irritate the pancreatic acini and result in an increase in the pancreatic secretions.

There are limited data stating that this helmnith was found in the main pancreatic duct leading to acute pancreatitis [11] and nasal expulsion [12]. In addition to being found in the biliary tree and gall bladder precipitating acalculous cholecystitis [13]-[16]. Patients infected with taenia have minimal gastrointestinal upset or might even be asymptomatic. Taenia saginata tapeworm tends to be 4 - 12 meters long. The adult tapeworms may generate roughly 100,000 offspring's/worm and 1000 to 2000 proglottids/worm. Taenia Solium, which is transmitted by eating pork and is 2 - 8 meters long, produces usually 1000 proglottids/worm, and might produce 50,000 offspring's/worm. Taenia Asiatica's lenghth is 4 - 8 meters long, producing 700 proglottids/worm and might produce 80,000 eggs per proglottid. Typical symptoms of taeniasis carry minimal abdominal discomfort, nausea, flatulence, diarrhea, or hunger pains. By far the major visible manifestation of taeniasis would be active passing of proglottids throughout the anus and in the feces. In occasional cases, proglottids can be embedded in the bile, pancreatic ducts or in the lumen of the appendix. The diagnosis is made by stool analysis and microscopic recognition of eggs and proglottids in feces. It takes 2 - 3 months for taenia to release eggs and proglottids in feces. To increase sensitivity, examination of 3 consecutive stool samples should be used. According to the Centers for Disease Control and Prevention (CDC), coproantigen and molecular assays that are lately established tend to be more sensitive than stool analysis. However, these new investigation methods are only available for research purposes.

Ultrasound is a great noninvasive tool for identification of helminths in the biliary tree [17], yet it is an operator dependent technique, where in our case, it was repeated twice by two different technicians. Endoscopic retrograde cholangiography (ERCP) is an excellent tool in detecting and extracting worms from the biliary system [18]. However, ERCP was not done for our patient, in order to avoid exposing her to the complications and risks of the procedure while she was improving. Rather, MRCP was done for further visualization of the pancreatic duct. 
Praziquantel is the most effective drug against helminths [11]. According to the CDC, it's given at dosage of 5 - $10 \mathrm{mg} / \mathrm{kg}$ orally once for both adults and children. Alternative drugs are niclosamide, albendazole or mebendazole which can be less effective and subjects are susceptible to recurrence [11] [19]. Nevertheless, we treated our patient with mabendazole, because it was the only drug available at that time.

Stool has to be re-checked for Taenia eggs at 1 and 3 months after giving the therapeutic regimen to verify that the infection is actually resolved.

\section{Conclusion}

Tapeworm induced recurrent pancreatitis happens seldom. In idiopathic recurrent pancreatitis, precise history and cautious investigations should be carried out in order to find out the cause of pancreatitis.

\section{Acknowledgements}

We gratefully acknowledge the contribution of Dr. Afnan Alattas, MBBS, senior radiology resident for her essential assistance. We also thank Dr. Abdulrahman Altaher, MBBS for his substantial support and helping with the literature review, Dr. Roaa Jambi, MBBS and Dr. Rawan Benkuddah, MBBS for their comments in preparing this manuscript.

\section{References}

[1] Sarles, H., Sarles, J.C., Camatte, R., Muratore, R., Gaini, M., Guien, C., Pastor, J. and Le Roy, F. (1965) Observations on 205 Confirmed Cases of Acute Pancreatitis, Recurring Pancreatitis, and Chronic Pancreatitis. Gut, 6, 545-559. http://dx.doi.org/10.1136/gut.6.6.545

[2] Steinberg, W. and Tenner, S. (1994) Acute Pancreatitis. The New England Journal of Medicine, 330, 1198-1210. http://dx.doi.org/10.1056/NEJM199404283301706

[3] Lee, S.P., Nicholls, J.F. and Park, H.Z. (1992) Biliary Sludge as a Cause of Acute Pancreatitis. The New England Journal of Medicine, 326, 589-593. http://dx.doi.org/10.1056/NEJM199202273260902

[4] Crompton, D.W. (1999) How Much Human Helminthiasis Is There in the World? Journal of Parasitology, 85, 397-403. http://dx.doi.org/10.2307/3285768

[5] Bordon, L.M. (1992) Intestinal Obstruction Due to Taenia saginata Infection: A Case Report. The Journal of Tropical Medicine and Hygiene, 95, 352-353.

[6] Karanikas, I.D., Sakellaridis, T.E., Alexiou, C.P., Siaperas, P.A., Fotopoulos, A.C. and Antsaklis, G.I. (2007) Taenia saginata: A Rare Cause of Bowel Obstruction. Transactions of the Royal Society of Tropical Medicine and Hygiene, 101, 527-528, http://dx.doi.org/10.1016/j.trstmh.2006.07.004

[7] Ozbek, A., Guzel, C., Babacan, M. and Ozbek, E. (1999) An Infestation Due to a Taenia saginata with an Atypical Localization. American Journal of Gastroenterology, 94, 1712-1713. http://dx.doi.org/10.1111/j.1572-0241.1999.01712.x

[8] Daou, R., Achram, M., Abousalbi, M. and Dannaoui, M. (1998) Acute Acalculous Cholecystitis Due to Taenia saginata. Chirurgie, 123, 195-197. http://dx.doi.org/10.1016/S0001-4001(98)80106-2

[9] Yellin, A.E. and Donovan, A.J. (1981) Biliary Lithiasis and Helminthiasis. The American Journal of Surgery, 142, 128-136. http://dx.doi.org/10.1016/S0002-9610(81)80022-0

[10] King, C.H. (2000) Cestodes (Tapeworms). In: Mandell, G.L., Bennett, J.E. and Dolin, R., Eds., Principles and Practice of Infectious Diseases, 5th Edition, Churchill Livingstone, Philadelphia, 2956-2964.

[11] Liu, Y.M., Bair, M.J., Chang, W.H., Lin, S.C. and Chan, Y.J. (2005) Acute Pancreatitis Caused by Tapeworm in the Biliary Tract. American Journal of Tropical Medicine and Hygiene, 73, 377-380.

[12] Sheikh, M., Sheikh, I., Ali, I. and Reshi, F. (2008) Nasal Expulsion of Taenia saginata: A Rare Route of Expulsion. The Internet Journal of Surgery, 16, Article 7.

[13] Benedict, E.B. (1926) Taenia saginata in the Gall Bladder. The Journal of the American Medical Association, 87, 1917. http://dx.doi.org/10.1001/jama.1926.92680230001012

[14] Talice, R.V. and Perez-Moreira, L. (1954) Localization of Taenia saginata in the Gallbladder. Archivos Uruguayos Medicina, Cirugia y Especialidades, 44, 261-269.

[15] Kim, Y.H., Chi, G.J. and Cho, S.-Y. (1981) A Case of Taenia saginata Infection Involving Gallbladder and Common Bile Duct. Korean Journal of Parasitology, 19, 167-172. http://dx.doi.org/10.3347/kjp.1981.19.2.167

[16] Daou, R., Achram, M., Abousalbi, M. and Dannaoui, M. (1998) Acute Acalculous Cholecystitis Due to Taenia sagi- 
nata. Chirurgie, 123, 195-197. http://dx.doi.org/10.1016/S0001-4001(98)80106-2

[17] Khuroo, M.S., Zargar, S.A., Mahajan, R., Bhat, R.L. and Jovid, G. (1987) Sonographic Appearances in Biliary Ascariasis. Gastroenterology, 93, 267-272.

[18] Khuroo, M.S. (1996) Ascariasis. Gastroenterology Clinics of North America, 25, 553-577. http://dx.doi.org/10.1016/S0889-8553(05)70263-6

[19] Ooi, H.K., Ho, C.-M. and Chung, W.-C. (2013) Historical Overview of Taenia asiatica in Taiwan. The Korean Journal of Parasitology, 51, 31-36. http://dx.doi.org/10.3347/kjp.2013.51.1.31 